Article

\title{
Russeting in Apple Is Initiated After Exposure to Moisture Ends-I. Histological Evidence
}

\author{
Yun-Hao Chen ${ }^{1}$, Jannis Straube ${ }^{2}$, Bishnu P. Khanal ${ }^{1, *} \mathbb{D}$, Moritz Knoche ${ }^{1}[$ and \\ Thomas Debener ${ }^{2}$ (D) \\ 1 Institute of Horticultural Production Systems, Fruit Science Section, Leibniz University Hannover, \\ Herrenhäuser Straße 2, 30419 Hannover, Germany; chen@obst.uni-hannover.de (Y.-H.C.); \\ moritz.knoche@obst.uni-hannover.de (M.K.) \\ 2 Institute of Plant Genetics, Molecular Plant Breeding Section, Leibniz University Hannover, \\ Herrenhäuser Straße 2, 30419 Hannover, Germany; straube@genetik.uni-hannover.de (J.S.); \\ debener@genetik.uni-hannover.de (T.D.) \\ * Correspondence: khanal@obst.uni-hannover.de; Tel.: +49-511-762-9004
}

Received: 13 September 2020; Accepted: 28 September 2020; Published: 30 September 2020

check for updates

\begin{abstract}
Russeting (periderm formation) is a critical fruit-surface disorder in apple (Malus $\times$ domestica Borkh.). The first symptom of insipient russeting is cuticular microcracking. Humid and rainy weather increases russeting. The aim was to determine the ontogeny of moisture-induced russeting in 'Pinova' apple. We recorded the effects of duration of exposure to water and the stage of fruit development at exposure on microcracking, periderm formation and cuticle deposition. Early on (21 or 31 days after full bloom; DAFB) short periods ( 2 to $12 \mathrm{~d}$ ) of moisture exposure induced cuticular microcracking-but not later on (66 or $93 \mathrm{DAFB}$ ). A periderm was not formed during moisture exposure but $4 \mathrm{~d}$ after exposure ended. A periderm was formed in the hypodermis beneath a microcrack. Russeting frequency and severity were low for up to $4 \mathrm{~d}$ of moisture exposure but increased after $6 \mathrm{~d}$. Cuticle thickness was not affected by moisture for up to $8 \mathrm{~d}$ but decreased for longer exposures. Cuticular ridge thickness decreased around a microcrack. In general, moisture did not affect cuticular strain release. We conclude that a hypodermal periderm forms after termination of moisture exposure and after microcrack formation. Reduced cuticle deposition may cause moisture-induced microcracking and, thus, russeting.
\end{abstract}

Keywords: russeting; periderm; Malus $\times$ domestica; surface moisture; cuticle; strain

\section{Introduction}

Russeting is a commercially important surface disorder of many fruit crop species, worldwide. Among other species affected are: apple [1], pear [2], grape [3] and prune [4]. The rough, brownish appearance of russeting renders a fruit unattractive to the consumer. Russeting also increases rates of postharvest moisture loss that lead to shriveling (fruit lose their fresh glossiness, so look old) and to higher rates of mass loss during storage, transport and retail (fruit are priced to the consumer on a per-kg basis) [5].

In anatomical terms, russeting represents a periderm comprising the phellem, a phellogen and a phelloderm [6,7]. The phellem cells (also referred to as cork cells) have suberized cell walls that are responsible for the dull and brownish color of a russeted fruit. These cork cells typically occur in stacks, resulting from division of the phellogen cells [8].

Information on how such a periderm is initiated in apple fruit skin is limited. Empirical evidence indicates that a range of factors may be involved. These include mechanical wounding [9], certain agrochemicals [10-12], epiphytic microorganism [13], insects (rust mites) [14] and diseases [15]. 
Of particular interest here is the effect of moisture on russeting in apple. Numerous studies indicate that exposure to surface wetness [16-18] or to high humidities [19] can be the cause of russeting in apple. Surface moisture, applied either as liquid-phase water or as vapor-phase water, induces microcracking in a number of fruit crop species, including apple [16]. Microcracks in the apple fruit skin are the first visible symptom of insipient russeting [20-22]. The mechanism of water-induced microcracking is not clear. It is possible that one of the factors is modification of the mechanical properties of the cuticle induced through changes in hydration [23].

We recently developed a system that reliably induces microcracking and russeting by local exposure of patches of the apple fruit surface to moisture [24]. Briefly, a length of tube is attached to the fruit surface using a non-phytotoxic silicone rubber. The tube is filled with water and periodically resealed to the fruit surface. The patch of skin included within the tube footprint first develops microcracks and, later, displays symptoms of russeting. These symptoms are microscopically identical to those observed on a fruit naturally exposed to surface moisture in the field. This system may be helpful in studying the mechanistic basis of russeting. It also avoids confusions associated with comparisons of different fruit genotypes or of different individual fruit or of different regions on the fruit surface. It allows critical comparisons to be made by imposing a moisture treatment to a defined patch of fruit skin, while an untreated (control) patch is defined in an equivalent region on the surface of the same fruit. It thereby allows standardization for a range of potential sources of response variability including stage of fruit development, differences in micro-environment, in orientation and in management (tree center vs. periphery etc.).

The specific objectives here were to identify the sequence of events that culminate in moisture-induced russeting. We were particularly interested to determine when and where a periderm is formed in relation to the location of moisture exposure. We focused on apple because apples are an important fruit crop species in both the northern and southern hemispheres and because russeting presents a problem to producers of this fruit crop.

\section{Results}

Following a $12 \mathrm{~d}$ exposure to moisture, a periderm had developed after an additional $8 \mathrm{~d}$ without moisture as indexed by stacks of fluorescing phellem cells visible in cross-sections of the skin (Figure 1). Furthermore, the typical russeting symptoms were visible at the fruit surface. There was no periderm and no russet visible in either of the moisture controls, regardless of the presence (or not) of the tube. Hence, we conclude that the periderm resulted from moisture exposure and not from the mounting of the tube. Because of this finding, there was no need to mount an empty tube as a control in subsequent experiments. 

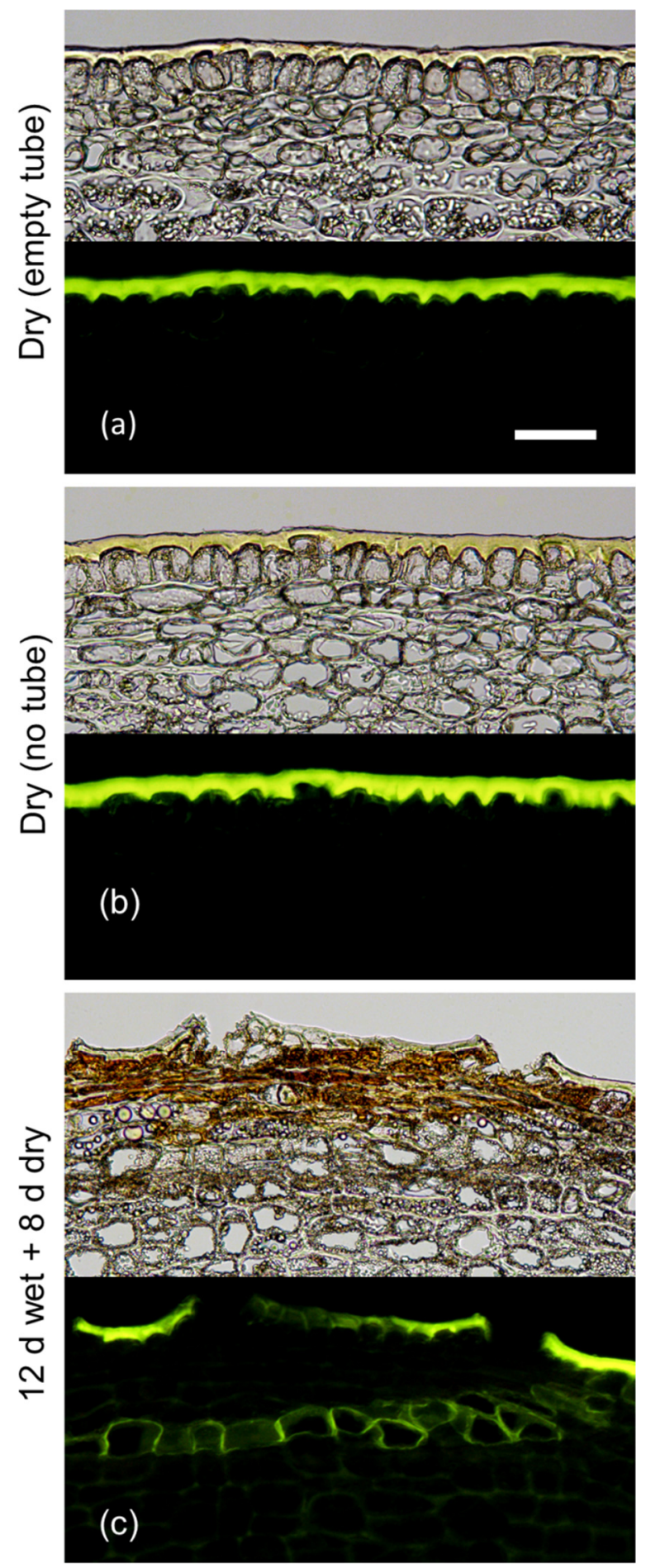

Figure 1. Effects of mounting tubes on the fruit surface without and with added moisture for $12 \mathrm{~d}$, on the formation of periderm $8 \mathrm{~d}$ after removal of the tubes. (a) control that had a tube without water mounted for $12 \mathrm{~d}$. (b) control without tube. (c) moisture treatment that had a tube containing water mounted for $12 \mathrm{~d}$. The experiment comprised two phases: Phase I consisted of mounting the tube without or with water and Phase II marks the period after termination of moisture treatment. Micrographs taken under transmitted white light (upper) or incident fluorescent light (lower) (filter module U-MWB) following staining with Fluorol Yellow 088. The scale bar in (a) is $50 \mu \mathrm{m}$ long and representative of all images in the composite $(n=3)$. 
Moisture exposure of the fruit surface at the young stage induced microcracks in the cuticle as indexed by increased infiltration of the fluorescent tracer acridine orange (Figure 2). Moisture exposure periods of 2 to $12 \mathrm{~d}$ resulted in significantly higher acridine orange infiltration as compared to the non-exposed control (Phase I, Figure 2). When the moisture exposure was terminated, the area infiltrated with acridine orange decreased to a level similar to that of the non-treated control (Phase II). The only exception was at $8 \mathrm{~d}$ after termination of the moisture treatment. By this time, rainfall had occurred in the orchard (Phase II, Figure 2).

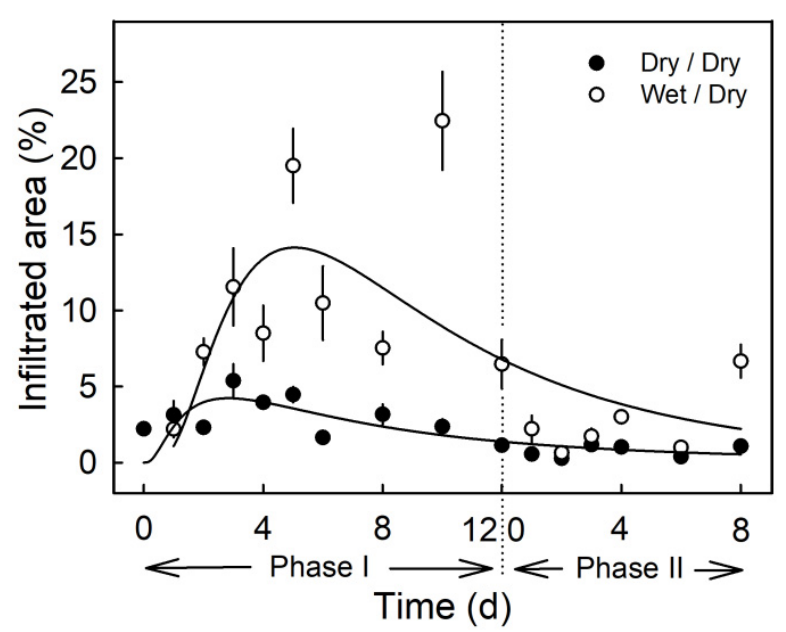

Figure 2. Time course of moisture-induced microcracking. Microcracking of the cuticle was indexed by quantifying the percentage of treated area infiltrated with acridine orange. The experiment comprised two phases: The first period of moisture exposure (Phase I) and the second period after termination of moisture exposure (Phase II). The end of Phase I and the beginning of Phase II is indicated by the dashed vertical line. The moisture treatment is referred to as 'wet/dry' and the control as 'dry/dry.' Data symbols present means \pm SE ( $n=6$ to 20$)$.

During exposure to moisture (Phase I), there was no indication of periderm formation from microscopy of cross-sections stained with Fluorol Yellow 088, regardless of exposure duration (6 or $12 \mathrm{~d}$; Figure 3). Microcracks had formed that traversed the cuticle. Following termination of moisture exposure (Phase II), a periderm developed by $4 \mathrm{~d}$ below the epidermis in the hypodermal cell layers. Periderm formation was indexed by stacks of cells that stained with Fluorol Yellow 088. These cells represented the typical cork cells (phellem) that originate from an underlying phellogen. There was no apparent difference between the periderms that formed after a $6 \mathrm{~d}$ or a $12 \mathrm{~d}$ period of moisture exposure.

Varying the duration of moisture exposure (Phase I) revealed that a minimum moisture period of $6 \mathrm{~d}$ was needed to induce a periderm within $4 \mathrm{~d}$ after moisture termination (Phase II). As in the previous experiment, there were no detectable changes in the fruit skin during moisture exposure except for the formation of microcracks. These were observed after $4 \mathrm{~d}$ of moisture exposure (Figure 4 ).

The frequency of russeted fruit and the percentage of russeted area were low for moisture exposures up to $4 \mathrm{~d}$ (Phase I) at the young stage (from 31 DAFB onwards) but increased markedly for moisture exposures of $6 \mathrm{~d}$ or longer. There was little difference in frequency of russeted fruit beyond $6 \mathrm{~d}$ moisture exposure (Figure 5a). However, the russeted areas continued to increase from 6 to $16 \mathrm{~d}$ of moisture exposure (Figure 5b). There was no moisture-induced russeting at maturity (156 DAFB), when surfaces were exposed to moisture for $12 \mathrm{~d}$ at 66 DAFB or at 93 DAFB ( $n=10-15$; data not shown).

Fruit exposed to moisture for $12 \mathrm{~d}$ beginning at 31 DAFB had developed russet at maturity (156 DAFB) and a multistack phellem typical for russeted apples was visible (Figure 6). By maturity, the cuticle and the remains of the epidermis and hypodermis had sloughed off and the brown color of the periderm was fully exposed at the surface. Furthermore, the micromorphology of the 
skin of moisture-treated fruit was identical to that of naturally russeted fruit of the same cultivar (data not shown).

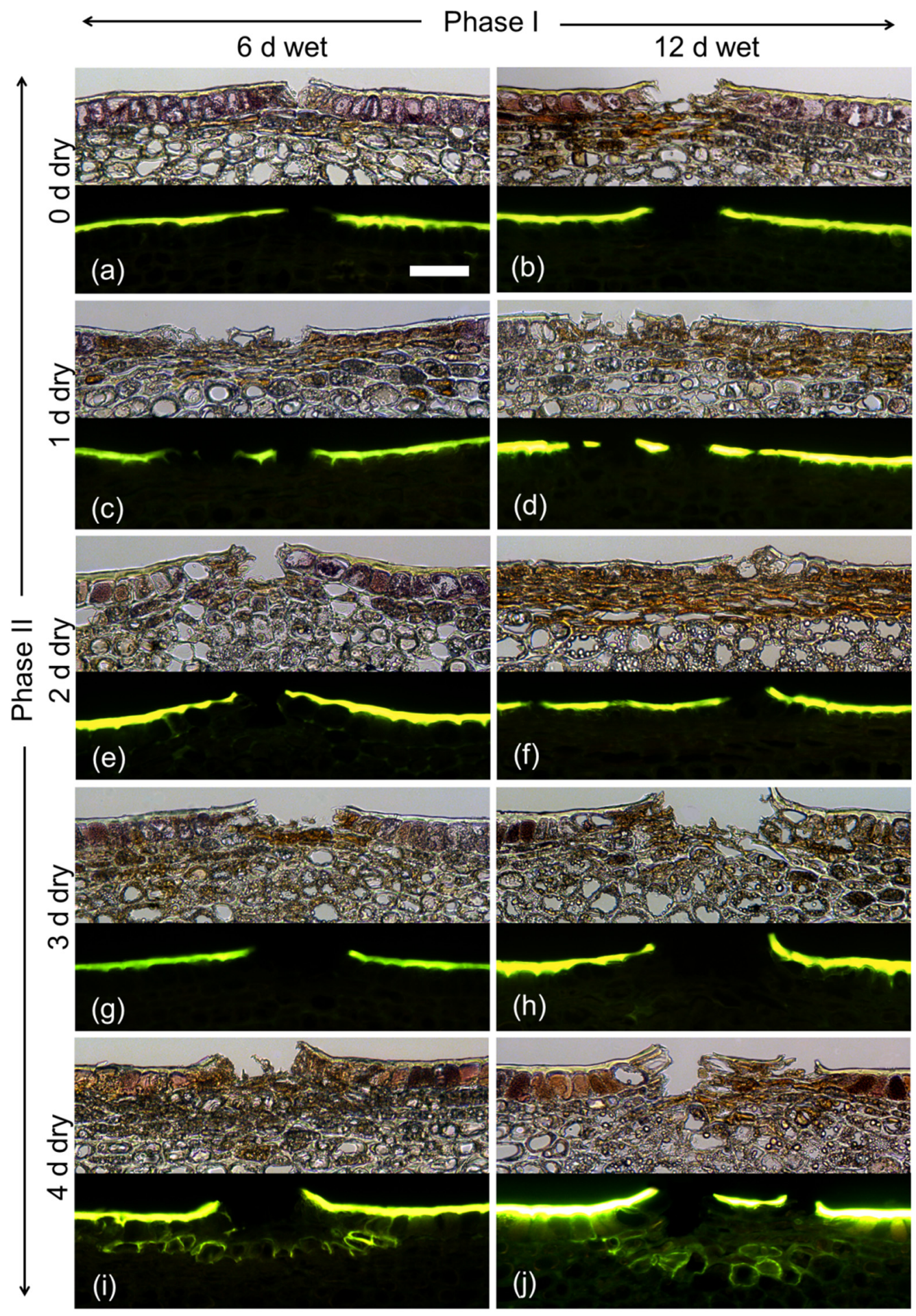

Figure 3. Effect of moisture exposure for $6 \mathrm{~d}(\mathbf{a}, \mathbf{c}, \mathbf{e}, \mathbf{g}, \mathbf{i})$ or for $12 \mathrm{~d}(\mathbf{b}, \mathbf{d}, \mathbf{f}, \mathbf{h}, \mathbf{j})$ on the time course of periderm development established at $0 \mathrm{~d}(\mathbf{a}, \mathbf{b}), 1 \mathrm{~d}(\mathbf{c}, \mathbf{d}), 2 \mathrm{~d}(\mathbf{e}, \mathbf{f}), 3 \mathrm{~d}(\mathbf{g}, \mathbf{h})$ or $4 \mathrm{~d}(\mathbf{i}, \mathbf{j})$ after termination of moisture exposure. The experiment comprised two phases: Phase I of moisture exposure and Phase II after termination of moisture exposure. Micrographs taken under transmitted white light (upper) or incident fluorescent light (lower) (filter module U-MWB) following staining with Fluorol Yellow 088. The scale bar in (a) is $50 \mu \mathrm{m}$ long and representative of all images in the composite $(n=3)$. 


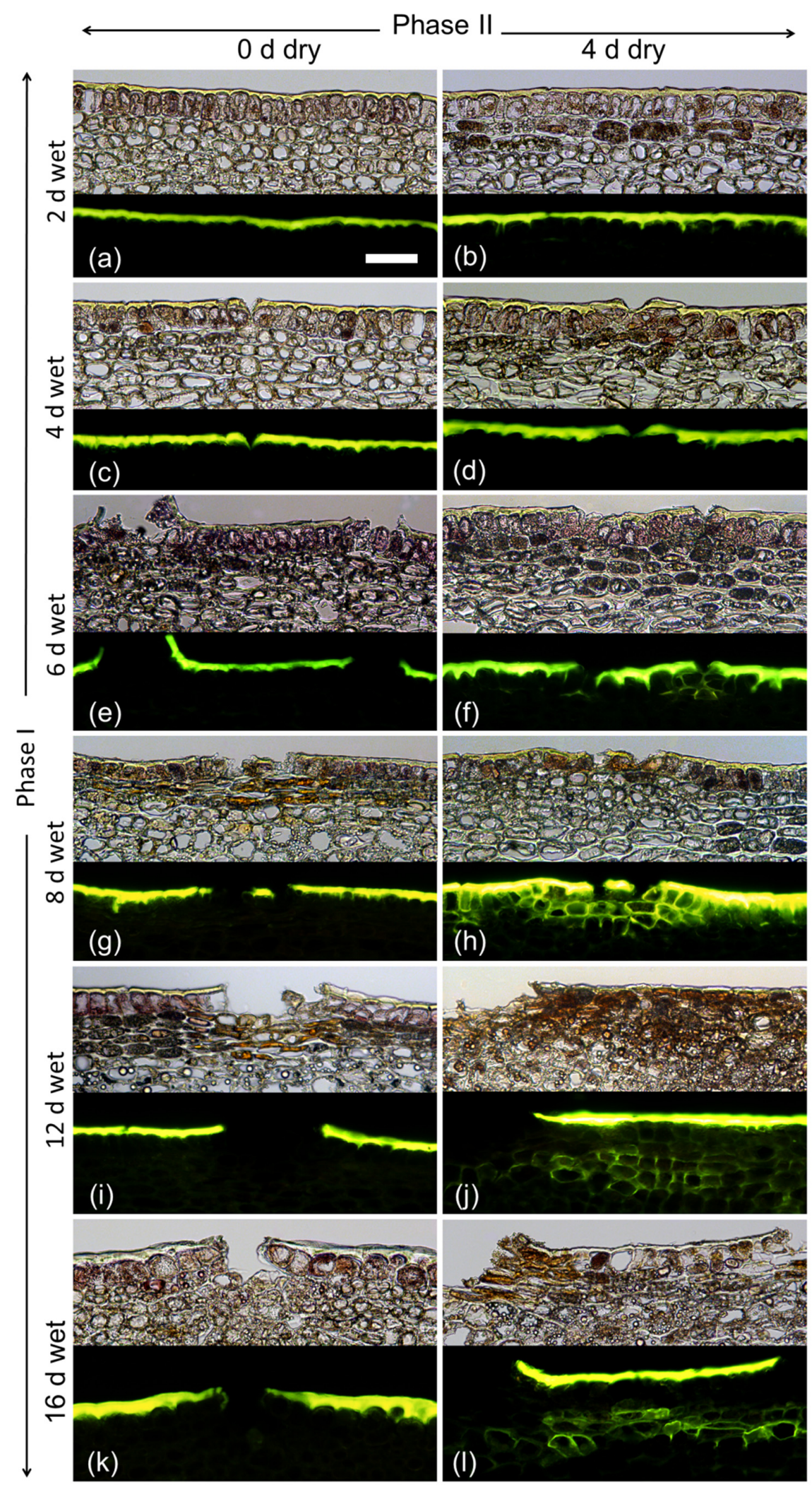

Figure 4. Effect of moisture exposure for $2 \mathrm{~d}(\mathbf{a}, \mathbf{b}), 4 \mathrm{~d}(\mathbf{c}, \mathbf{d}), 6 \mathrm{~d}(\mathbf{e}, \mathbf{f}), 8 \mathrm{~d}(\mathbf{g}, \mathbf{h}), 12 \mathrm{~d}(\mathbf{i}, \mathbf{j})$ or $16 \mathrm{~d}(\mathbf{k}, \mathbf{l})$ on periderm formation. The experiment comprised two phases: Phase I-time of moisture exposure and Phase II-time after termination of moisture exposure. Phase I was recorded immediately after termination of moisture exposure $(0 \mathrm{~d})(\mathbf{a}, \mathbf{c}, \mathbf{e}, \mathbf{g}, \mathbf{i}, \mathbf{k})$. Phase II was recorded $4 \mathrm{~d}$ after termination of moisture exposure $(\mathbf{b}, \mathbf{d}, \mathbf{f}, \mathbf{h}, \mathbf{j}, \mathbf{l})$. Micrographs taken under transmitted white light (upper) or incident fluorescent light (lower) (filter module U-MWB) after being stained with Fluorol Yellow 088. The scale bar in (a) is $50 \mu \mathrm{m}$ long and representative of all images in the composite $(n=3)$. 


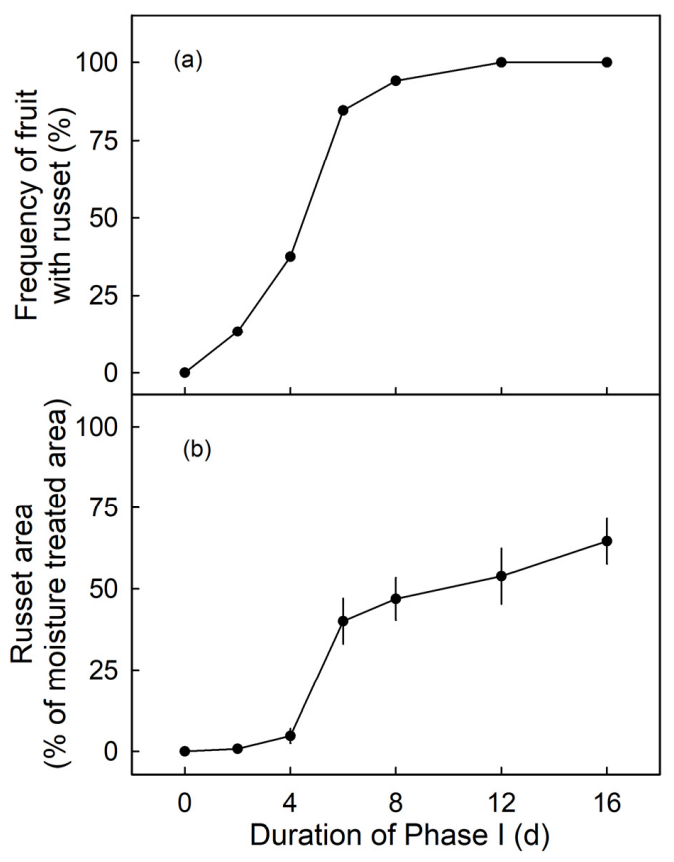

Figure 5. Effect of duration of moisture exposure (Phase I) on the frequency of russeted fruit (a) and the percentage of the moisture-exposed area that is russeted at maturity (156 days after full bloom; DAFB) (b). Fruits were exposed to moisture starting from 31 DAFB for $0,2,4,6,8,12$ or $16 \mathrm{~d}$. Data represent means \pm SE $(n=9-31)$.
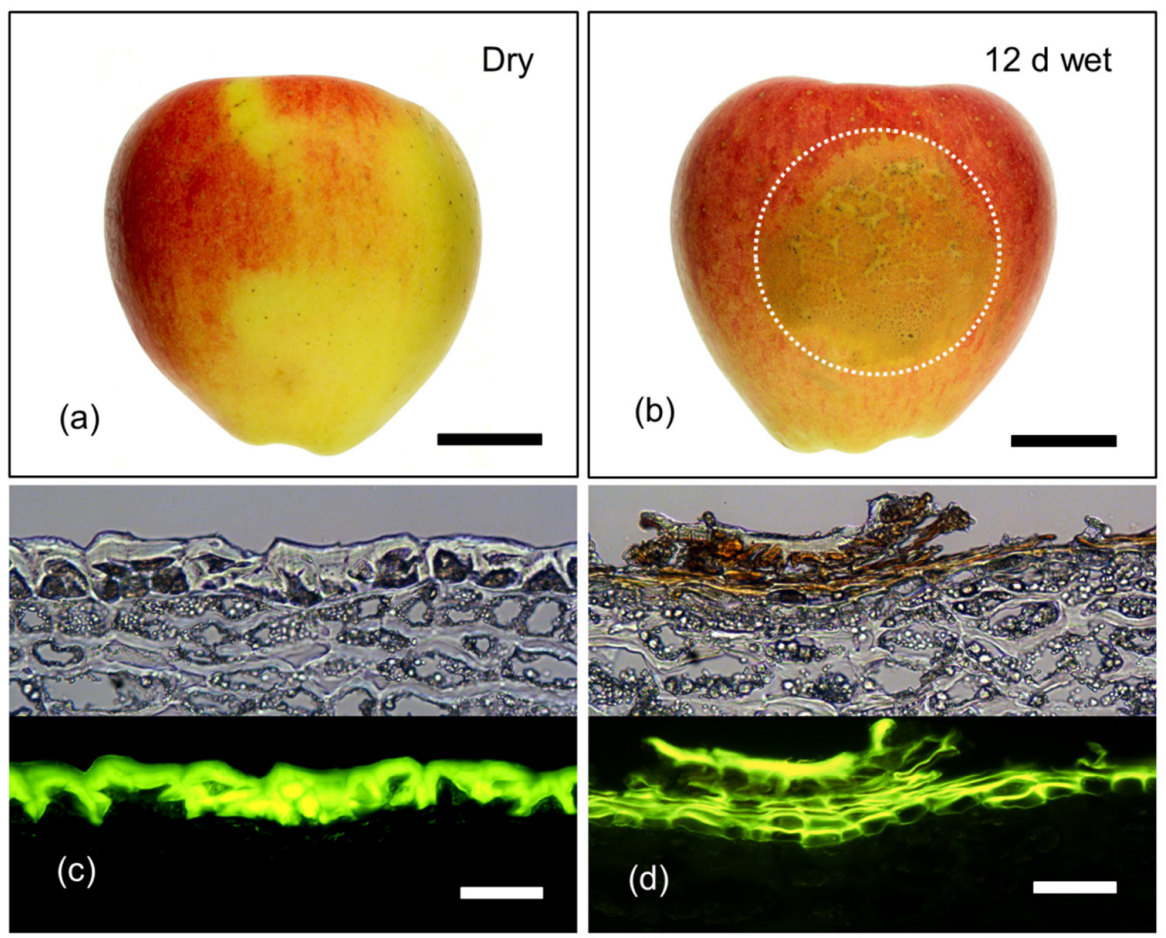

Figure 6. Macrographs (a,b) and micrographs (c,d) of mature (156 days after full bloom; DAFB) 'Pinova' apple fruit following exposure to surface moisture for $12 \mathrm{~d}$ at 31 DAFB (wet). Fruit without moisture-exposure, served as controls (dry). Micrographs represent cross-sections of the fruit skin in the moisture-exposed region and the dry region. Micrographs were taken under transmitted white light (upper) or incident fluorescent light (lower) (filter module U-MWB) after being stained with Fluorol Yellow 088. The area enclosed by the dotted circle represents the footprint of the moisture-treated patch of skin that subsequently developed russet. Scale bar in (a) and (b) is $2 \mathrm{~cm}$ long and that in (c) and (d) is $50 \mu \mathrm{m}$ long. 
The developmental time course revealed that $12 \mathrm{~d}$ moisture exposure induced periderm at 31 DAFB but not at 66 or 93 DAFB (Figure 7). Interestingly, microcracks were observed only following moisture exposure at 31 DAFB but not at 66 or 93 DAFB (Figure 7).

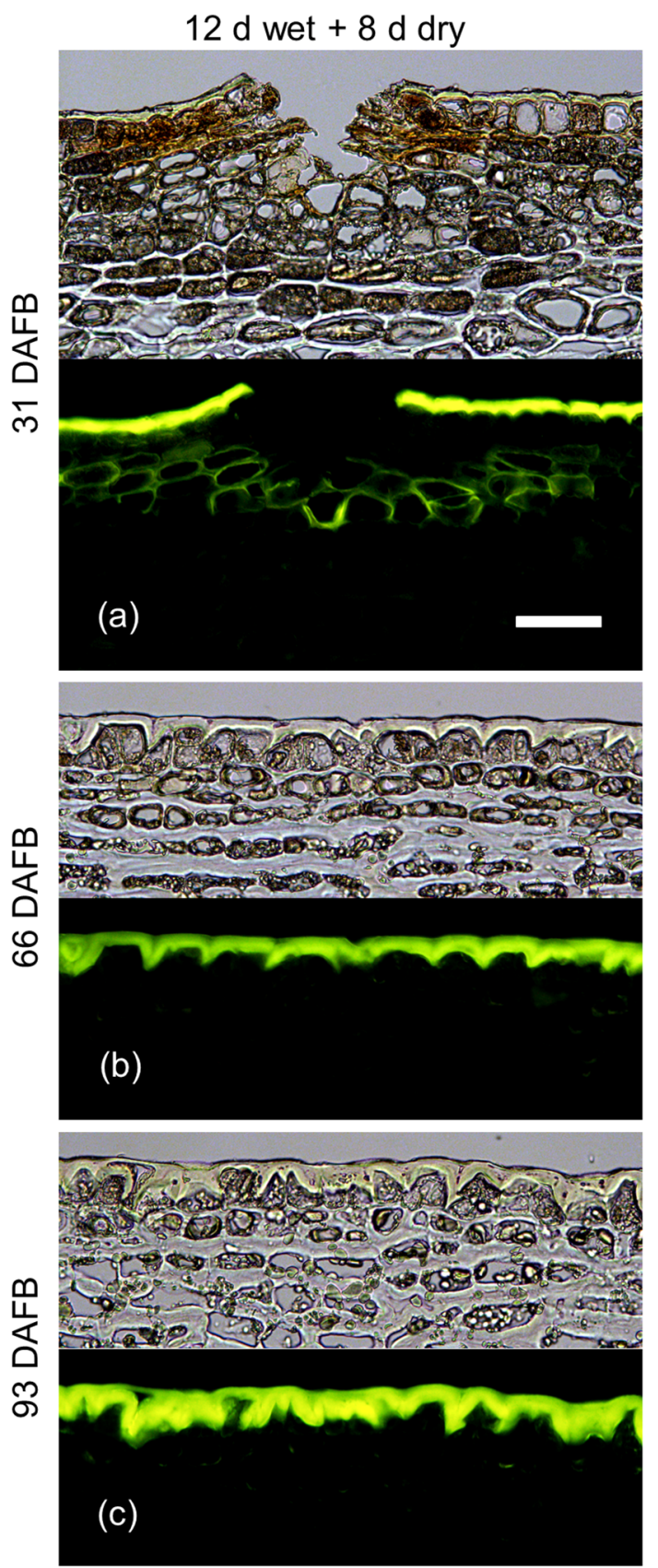

Figure 7. Effect of a $12 \mathrm{~d}$ moisture exposure (wet; Phase I) on periderm development in the skin of apple fruit. Cross-sections were prepared $8 \mathrm{~d}$ after termination of moisture exposure (dry; Phase II). The fruit surface was exposed to moisture starting at 31 days after full bloom (DAFB) (a) or 66 DAFB (b) or 93 DAFB (c). Cross-sections were prepared from the moisture-treated surface of the fruit. Images were taken under transmitted white light (upper) or incident fluorescent light (lower) (filter module U-MWB) after being stained with Fluorol Yellow 088. The scale bar in (a) is $50 \mu \mathrm{m}$ long and representative of all images in the composite $(n=3)$. 
Moisture had no effect on cuticle thickness during the first $8 \mathrm{~d}$ of exposure, nor on the ridges of the cuticular membrane (CM) above the anticlinal cell walls, nor on the lamellae above the periclinal cell walls (Phase I, Figure 8). From the day of moisture removal onwards, the thickness of the cuticle of the previously exposed patch increased at a lower rate comparable to that of the non-exposed control patch (Phase II, Figure 8).

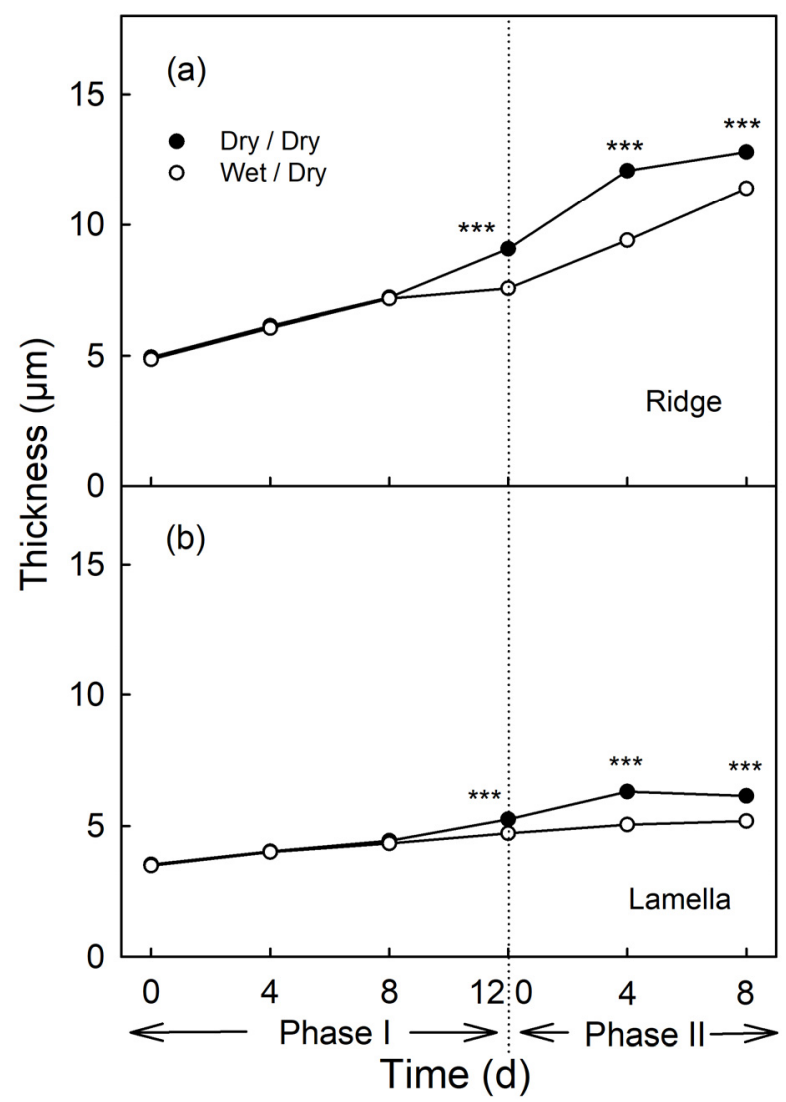

Figure 8. Effect of moisture exposure on the thickness of the cuticle above the anticlinal cell walls (ridge) (a) and above the periclinal cell walls (lamella) (b) of the apple fruit skin. In Phase I, the fruit was exposed to moisture for $12 \mathrm{~d}$. Phase II began following termination of moisture exposure (indicated by the dotted vertical line) and the surface remained dry thereafter (wet/dry). Fruit surface without moisture exposure served as control (dry/dry). ${ }^{* * *}$ indicate significant difference between 'dry/dry' and 'wet/dry' treatment at $p<0.001$. Data represent means \pm SE $(n=6)$.

The thicknesses of the CM ridges were lowest in the immediate vicinity of a microcrack. As distance increased, the CM thickness increased and approached the mean thickness averaged across the micrograph. This was also the case $4 \mathrm{~d}$ and $8 \mathrm{~d}$ after termination of the moisture treatment (Phase II, Figure 9).

Neither moisture exposure (Phase I) and nor the termination of moisture exposure (Phase II) had an effect on strain release following preparation of the excised skin segments (ES) and isolation of the $\mathrm{CM}$ (Figure 10a). However, the strain release after wax extraction was higher during Phase I and after exposure to moisture (Phase II) than of the non-exposed control (Figure 10b). The difference in strain release between exposed and non-exposed CM increased up to about $6 \mathrm{~d}$ after the beginning of exposure and then remained approximately constant (Figure 10b). Calculating total strain from the two component strains revealed that the $\varepsilon_{t o t}$ increased during moisture exposure (Phase I). The rate of increase was somewhat higher for the $\varepsilon_{t o t}$ from the moisture treatment than for the control. The difference in $\varepsilon_{\text {tot }}$ decreased slightly when moisture exposure was terminated (Phase II; Figure 10c). 

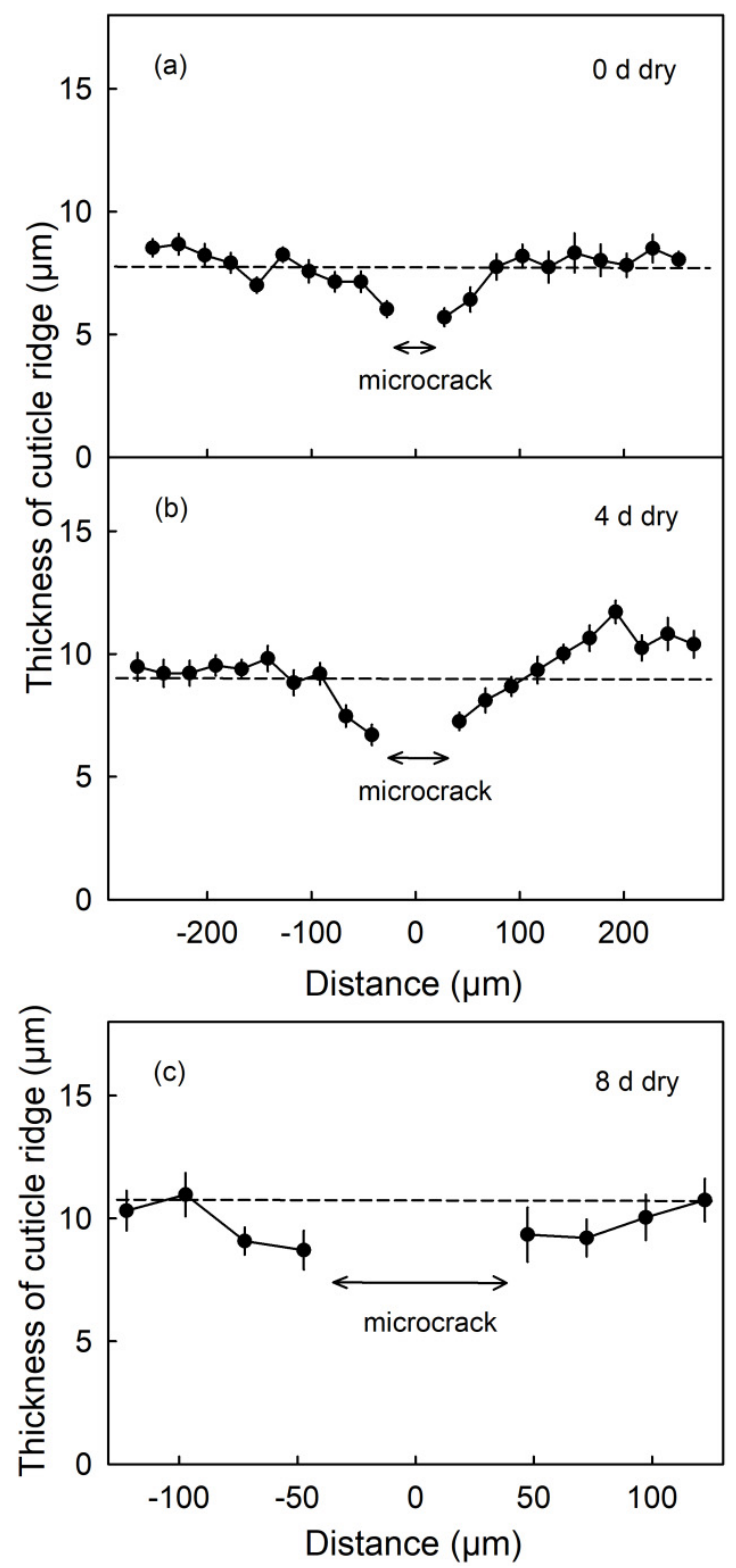

Figure 9. Thickness of the cuticle above the anticlinal cell walls (ridge) as affected by the distance from a moisture induced microcrack. Microcracks were induced by $12 \mathrm{~d}$ of moisture exposure. Thickness was measured on cross-sections of the fruit skin prepared from fruit sampled on the day of termination of moisture exposure ( $0 \mathrm{~d})(\mathbf{a})$ and $4 \mathrm{~d}(\mathbf{b})$ and $8 \mathrm{~d}$ (c) after moisture termination (during Phase II). The distance ' 0 ' represents the center of the microcrack. Thickness was measured in both directions from the microcrack. The dashed line is the grand mean thickness of all cuticle ridges within the micrograph. The arrows indicate the mean width of the microcrack. Data represent means \pm SE of 14 to 19 microcracks on a total of six fruits. 


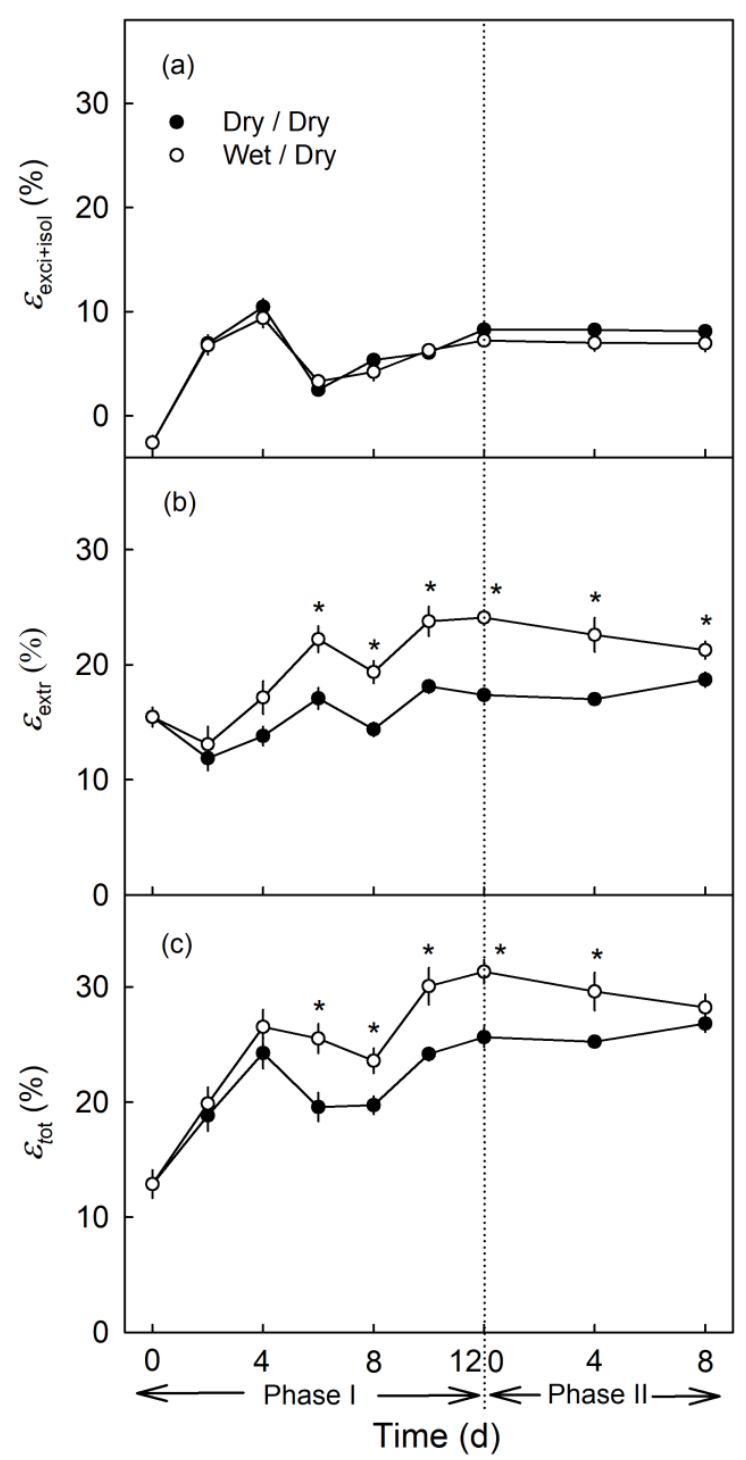

Figure 10. Effect of $12 \mathrm{~d}$ of moisture exposure (Phase I) on the elastic strain of the cuticular membrane (CM). Strain was quantified as the strain release during excision and isolation of the $\mathrm{CM}\left(\varepsilon_{\text {exci }+ \text { isol }} ; \mathbf{a}\right)$ and following wax extraction of the CM $\left(\varepsilon_{\text {extr }} ; \mathbf{b}\right)$ and the sum of $\varepsilon_{\text {exci+isol }}$ plus $\varepsilon_{\text {extr }}\left(\varepsilon_{\text {tot }} ; \mathbf{c}\right)$. Phase I represents the period of moisture exposure (wet). Phase II represents the period after moisture termination (dry). The dotted line indicates the end of Phase I and the beginning of Phase II. * indicates a significant difference between dry/dry and wet/dry treatment at $p<0.05$. Data represent means $\pm \mathrm{SE}$ $(n=8$ to 20$)$.

\section{Discussion}

Our results establish two important findings-(1) Periderm formation in young 'Pinova' apple fruit is not induced during moisture exposure but after termination of moisture exposure and (2) decreased rate of cuticle deposition contributes to moisture-induced microcracking.

\subsection{Periderm Formation in Young Fruit Is not Induced During Moisture Exposure but After Termination of Moisture Exposure}

Our study is consistent with earlier observations [20]. First, microcracks traversing the cuticle are the first visible symptom in moisture-induced russeting. We have not found a single instance where russet formation was not preceded by microcracking. Second, the periderm formed in the hypodermis, beneath the cuticle and epidermis was as described by Meyer [22] and Pratt [25]. Third, 
early stages of fruit development were most susceptible to russet $[1,20,26,27]$. Indeed, no russeting occurred following exposure to moisture at later stages of fruit development. Fourth, our experimental approach provides conclusive evidence that surface moisture is the cause of russeting. A role of surface moisture in russeting has been suggested previously [18,19,24,28].

Our results consistently show that periderm formation is triggered following termination of the moisture treatment-not during it. This conclusion is based on the observation that increased durations of exposure to moisture beyond a minimum of $4 \mathrm{~d}$ had no effect on periderm formation. Regardless of the duration of moisture exposure, a periderm always formed about $4 \mathrm{~d}$ after moisture termination. This implies (1) that it is not microcracking per se that triggers russet formation and (2) that some sort of signal must be involved that has its source at the site of microcracking (the cuticle) and travels through two or three cell layers to the subtending hypodermis where the periderm is initiated. Whatever the nature of this signal, it triggers the process involved in the formation of a periderm. This process involves the dedifferentiation of a layer of cells in the hypodermis and their subsequent differentiation into a phellogen which divides repeatedly to produce a stack of suberized phellem cells [7].

Candidates for this signal could include mechanical stimuli, such as the one associated with the release of reversible strain (i.e., elastic and viscoelastic strains) when a microcrack forms in the cuticle. However, several arguments suggest this is unlikely to be the stimulus. First, there was little strain release on excision of an ES and on the isolation of the CM, thus indicating the absence of significant elastic strain in the apple fruit cuticle. This observation is consistent with an earlier one of Lai et al. [29]. Second, the contribution of the cuticle to the overall mechanical properties of the skin is small [30]. It is the epidermis and the hypodermis that together represent the structural backbone of the skin of an apple fruit. Third, if strain relaxation were a factor, one would expect periderm formation to begin after microcrack formation, that is, during moisture exposure (Phase I), not after a fixed time following termination of moisture exposure. We conclude that a mechanical signal is unlikely to be the cause.

An alternative signal candidate may be the change in the barrier properties of the microcracked cuticle. This type of signal could account for a response induced after removal of the tube. Furthermore, the remote response would also be accounted for. Changes in the chemical potential of substances for which the cuticle forms a primary barrier are probably candidates for such a signal. Following the formation of a microcrack, these substances will now move more freely across the skin. Such substances include the chemical potential of both liquid and vapor-phase water (the water potential) and the chemical potentials (partial pressures, concentrations) of dissolved moieties such as $\mathrm{O}_{2}, \mathrm{CO}_{2}$ and $\mathrm{C}_{2} \mathrm{H}_{4}$. The consequences of a suddenly less-restricted movement of water would be a change in water potential and thus of turgor. For a change of the chemical potential of the respiratory gases, for example, a decrease in $\left[\mathrm{CO}_{2}\right]$ or an increase in $\left[\mathrm{O}_{2}\right]$, there would likely be a change in $\mathrm{pH}$. Whether these are the changes that trigger periderm formation is not known.

\subsection{Moisture Exposure Increases Microcracking by Decreasing Cuticle Deposition}

A causal role for moisture in microcracking has been documented for a number of fruit crop species including sweet cherry [31], apple [18,24], grapes [32], mango [33]. Several factors are involved in formation of microcracks. First, a mismatch of surface expansion rate and cuticle deposition rate causes increased elastic strain [29,34] leading to failure of the cuticle [35]. Second, moisture may exacerbate microcracking by altering the mechanical properties of the cuticle [23,31]. Third, our results suggest that cuticle deposition is reduced as a consequence of moisture exposure and this will likely increase microcracking. The CMs isolated from moisture-exposed regions showed a higher elastic strain than CMs from the control surfaces that remained dry. This could well have been due to decreased deposition of cuticle (cutin and wax) due to moisture exposure. That wax plays an important role, is inferred from the marked differences in strain release on extraction between the moisture treatment and the control. Earlier studies established that depositions of wax in the expanding cutin network on a growing fruit surface substantially reduce build-up of elastic strain by converting the elastic strain into a plastic strain [36]. Further, deposition of new layers of cutin underneath the existing old layers 
fixes the elastic strain of the CM [37]. Continuing cutin and wax deposition will therefore fix the elastic strain in the dry control skins but to a lesser extent in the skins exposed to moisture. This would result in greater strain release upon wax extraction in the control, as compared to the conditions found in the moisture treatment. Further molecular and biochemical evidence is needed to draw a firmer conclusion on this point.

\subsection{Conclusions}

The exposure of discrete patches of the fruit skin of an apple to moisture induces the formation of a periderm after termination of the moisture treatment and after the formation of microcracks. The search for a signal that links the formation of cuticular microcracks, on the fruit surface, to the initiation of dedifferentiation and redifferentiation in the hypodermis, several cell layers below, must focus on this time slot. Our results provide indirect evidence that reduced cuticle deposition and, in particular, reduced wax deposition, is the result of moisture exposure and contributes to the formation of microcracks.

\section{Materials and Methods}

\subsection{Plant Materials}

'Pinova' apple trees (Malus $\times$ domestica, Borkh.) grafted on M9 rootstocks were cultivated at the Horticultural Research Station of the Leibniz University Hanover at Ruthe, Germany (52 $14^{\prime} N^{\prime}, 9^{\circ} 49^{\prime}$ E) according to current regulations for integrated crop production. The planting year was 1999, the experiments were conducted in the 2016, 2018 and 2019 growing seasons. Mean daily temperatures, mean daily precipitation and the daily radiation are provided as a supplemental file (Table S1). 'Pinova' was selected because it responded consistently to moisture exposure by russeting (Khanal, unpublished data). Vigorous flower clusters were selected randomly from a total of 125 trees at full bloom ( 0 days after full bloom; DAFB) and thinned to one flower, so that only the king flower remained. Fruitlets without visual defects and of uniform size and color were selected for the experiments.

\subsection{General Experimental Procedures}

\subsubsection{Moisture Treatment}

Moisture was applied locally to a defined patch on the fruit surface [24]. Briefly, a polyethylene tube (8 $\mathrm{mm}$ inside diameter; Sarstedt, Nümbrecht, Germany) was cut to a $17 \mathrm{~mm}$ length and mounted on the fruit surface in the equatorial region using a non-phytotoxic, fast-curing silicone rubber (Dowsil ${ }^{\mathrm{TM}}$ SE 9186 Clear Sealant, Dow Toray, Tokyo, Japan). Deionized water was introduced through the open end of the tube and this open end was then sealed with silicone rubber. In this way, the patch of skin exposed to liquid water was limited to that enclosed within the tube (ca. $50 \mathrm{~mm}^{2}$ ). To avoid leakage, the silicone seal between tube and fruit was renewed every $2 \mathrm{~d}$ until the moisture treatment was terminated. An equivalent patch of skin was identified on the opposite face of the same fruit to serve as the control. Unless specified otherwise, no tube was mounted over the control patch. Earlier experiments established that russeting was due to moisture exposure and not to the mounting of the tube [24]. On the day moisture exposure was terminated, the tube was removed and the fruit surface dried with a soft paper tissue. The tube detached very easily from the epidermis, so that no significant physical force was needed and the fruit surface displayed no visible sign of injury. The footprints of the treated and control patches on each fruit were delineated using a permanent marker. A particular fruit was either sampled immediately or left on the tree for later evaluation. Following sampling, a fruit was transferred to the laboratory within $3 \mathrm{~h}$. Intact fruit (21 or $31 \mathrm{DAFB}$ ) or sections of the fruit (66 or 93 DAFB) were stored in Karnovsky fixative [38] or immediately processed fresh, as described below. 


\subsubsection{Microcracks}

Microcracks were quantified in both the 2018 and 2019 growing seasons following the procedure described earlier $[24,35]$. Briefly, whole fruit were dipped in a $0.1 \%(w / v)$ aqueous acridine orange solution (Carl Roth, Karlsruhe, Germany) for $10 \mathrm{~min}$, rinsed with distilled water and carefully blotted dry using a soft paper tissue. The treated and the control patches of the skin were inspected using fluorescence microscopy (MZ10F; GFP-plus filter, 440-480 nm excitation, $\geq 510 \mathrm{~nm}$ emission wavelength; Leica Microsystems, Wetzlar, Germany) and imaged with a DP71 camera (Olympus Europa, Hamburg, Germany). Three or four images were recorded from different locations within each treated or control patch, on each of a total of six to ten fruit per sampling date. The areas $\left(\mathrm{mm}^{2}\right)$ infiltrated by acridine orange were quantified using image analysis (Cell ${ }^{\mathrm{P}}$, Olympus, Hamburg, Germany). The total fluorescing area within each treated (or control) patch, in each image, was calculated and was expressed as a percentage of the whole treated (or control) patch to which it referred.

\subsubsection{Cross-Section of Fruit Skin}

Tissue blocks (ca. $3 \mathrm{~mm}$ thick) comprising the fruit skin and some subtending parenchyma cells were excised from the treated or the control patches of the fixed fruit using a scalpel. The blocks were rinsed in distilled water and immersed in $70 \%(v / v)$ aqueous ethanol for $16 \mathrm{~h}$. The blocks were then dehydrated in an ascending series of ethanol $(80 \%, 90 \%$ and $96 \% v / v ; 30 \mathrm{~min}$ each) under a partial vacuum (pressure $10.8 \mathrm{kPa}$ ). Subsequently, the blocks were transferred to $100 \%$ isopropanol for 40 min (twice) and a xylene substitute (AppliClear; AppliChem, Münster, Germany) for 40 min (twice) to displace the ethanol in the tissues, under the same partial vacuum. The dehydrated blocks were then infiltrated with a 1:1 (v/v) paraffin/xylene substitute mixture (Carl Roth) for 40 min (once) and paraffin alone for $40 \mathrm{~min}$ (twice). Finally, the blocks were embedded in paraffin. The paraffin blocks so obtained were cooled and stored at $4{ }^{\circ} \mathrm{C}$ pending later sectioning.

Thin sections $(10 \mu \mathrm{m})$ were cut using a rotary microtome (Hyrax M 55, Zeiss, Germany). Sections were transferred to microscope slides, dried in an oven for $16 \mathrm{~h}$ at $38{ }^{\circ} \mathrm{C}$ and rehydrated as follows: xylene substitute ( $2 \times 10 \mathrm{~min})$; descending series of ethanol $(96 \%, 80 \%, 70 \%$ and $60 \%$ for $10 \mathrm{~min}$ each) and finally for $2 \times 5 \mathrm{~min}$ in distilled water.

\subsubsection{Microscopy}

Sections were stained for $1 \mathrm{~h}$ with 0.005\% Fluorol Yellow 088 (Santa Cruz Biotechnology, Texas, USA) [39] dissolved in 90\% glycerol and melted polyethylene glycol 4000 (SERVA Electrophoresis, Heidelberg, Germany). The sections were transferred to the stage of a fluorescence microscope (BX-60 equipped with a DP 73 digital camera; Olympus and viewed in transmitted white light or under incident fluorescent light (filter U-MWB; $450-480 \mathrm{~nm}$ excitation; $\geq 520 \mathrm{~nm}$ emission wavelength; Olympus, Hamburg, Germany). The minimum number of biological replicates was three. To confirm the occurrence of a periderm, a minimum of 50 sections through the whole block were examined.

\subsubsection{Cuticle Thickness Measurement}

Cross-sections of the skin from the moisture treated and the control patches were inspected at $\times 200$ in white light using a fluorescence microscope (BX-60; Olympus, Hamburg, Germany). The thickness of the $\mathrm{CM}$ above the anticlinal cell walls (ridge) or above the periclinal cell walls (lamella) were measured in two sets of images using image analysis (CellSens; Olympus, Hamburg, Germany). The first set comprised images selected for the absence of cuticular cracks. The thickness of the lamella and ridge were measured in a $350 \mu \mathrm{m}$ long transect. For this, four images per fruit from a total of six fruits were used. For the second set, images were selected which had a single cuticular crack. Here, the width of the crack and the thickness of the cuticular ridges were measured in a $275 \mu \mathrm{m}(0 \mathrm{~d}$ and $4 \mathrm{~d})$ or $125 \mu \mathrm{m}$ ( $8 \mathrm{~d})$ long transect from the center of the crack to either side. A total of 14 to 19 images on six fruits were used. 


\subsubsection{Russet Quantification}

Mature fruit were harvested at 156 DAFB. Digital calibrated images (Canon EOS 550D, lens: EF-S 18-55 mm, Canon Germany, Krefeld, Germany) were taken from the moisture treated and control patches on the fruit surface. The areas $\left(\mathrm{mm}^{2}\right)$ of the russeted spots on the fruit surface (as indexed by their brownish, rough, corky appearance) were quantified (Cell ${ }^{\mathrm{P}}$; Olympus, Hamburg, Germany) and summed within each patch of skin enclosed by the tube. The area of russet is expressed as a percentage of the area of the patch. The number of replicates ranged from 9 to 31.

\subsubsection{Cuticle Isolation and Strain Analysis}

The ES were punched from the treated and control patches using a biopsy punch ( $8 \mathrm{~mm}$ diameter; Kai Europe, Solingen, Germany; 10 and 12 mm diameter; Acuderm, Terrace, FL, USA). The CMs were isolated enzymatically by incubating the ES in an isolation medium containing pectinase $(9 \%, v / v$; Panzym Super E flüssig; Novozymes A/S, Krogshoejvej, Bagsvaerd, Denmark) and cellulase (0.5\% v/v; Cellubrix L.; Novozymes A/S) in a $50 \mathrm{mM}$ citric acid buffer at $\mathrm{pH} 4.0$ at ambient temperature [40]. $\mathrm{NaN}_{3}$ was added at a final concentration of $30 \mathrm{mM}$ to prevent microbial growth. Enzyme solutions were replaced periodically until CM separated from adhering cellular debris (about 4 weeks). The isolated $\mathrm{CMs}$ were carefully cleaned using a soft camel-hair brush. The $\mathrm{CM}$ were rinsed in distilled water, dried at $40{ }^{\circ} \mathrm{C}$ for a minimum period of $16 \mathrm{~h}$ and stored in multi-well cell culture plates held in polyethylene boxes above dry silica gel. For determination of the wax mass, the CM discs were extracted for $2 \mathrm{~h}$ using $\mathrm{CHCl}_{3} / \mathrm{MeOH}(1: 1, v / v$; Carl Roth) in a Soxhlet apparatus. The dewaxed CMs are referred to as DCMs.

The elastic strain was quantified using the procedure described in Lai et al. [29] with minor modifications. The CMs were rehydrated, placed on a microscope slide, flattened by placing a coverslip on top and then imaged under a dissecting microscope (Wild M10; Leica Microsystems; camera DP71). For the DCMs, the discs were transferred from the $\mathrm{CHCl}_{3} / \mathrm{MeOH}$ to $\mathrm{MeOH}$ and then directly to water, before being positioned on a microscope slide and flattened as described above. The areas of the $\mathrm{CM}$ and DCM discs were quantified by image analysis (Cell ${ }^{\mathrm{P}}$; Olympus, Hamburg, Germany).

The strains released following excision of the ES and isolation of the $\mathrm{CM}\left(\varepsilon_{\text {exci+isol }}\right)$ and following wax extraction $\left(\varepsilon_{\text {extr }}\right)$ were calculated as follows:

$$
\begin{gathered}
\varepsilon_{\text {exci+isol }}=\frac{A-A_{C M}}{A_{D C M}} \times 100 \\
\varepsilon_{\text {extr }}=\frac{A_{C M}-A_{D C M}}{A_{D C M}} \times 100 \\
\varepsilon_{\text {tot }}=\varepsilon_{\text {exci }+ \text { isol }}+\varepsilon_{\text {extr }} .
\end{gathered}
$$

In this equation, $A$ represents the area of the disc on the fruit surface before excision, that is, the cross-sectional area of the biopsy punch corrected for curvature of the disc. The $A_{C M}$ and $A_{D C M}$ represent the areas of the isolated CM and the extracted DCM. Because the $\varepsilon_{\text {exci+isol }}$ and the $\varepsilon_{\text {extr }}$ are additive, the total strain $\varepsilon_{t o t}$ equals the sum of the two component strains. The number of replicates ranged from 8 to 20 .

\subsection{Experiments}

All experiments were conducted in two phases: the moisture treatment was imposed during Phase I. The moisture treatment was then terminated, the tube removed and the treated patch now opened up to the natural atmosphere of the orchard-this second period was Phase II. The following experiments were conducted:

(1) The first experiment established that moisture exposure was the cause of periderm formation (and not the mounting of a polyethylene tube using silicone sealant). The experiment was conducted at 28 DAFB and comprised a control (without tube, without water) and the following two treatments: 
(i) an empty $8.5 \mathrm{~mm}$ long tube (no added water) with its distal end left open to the atmosphere and (ii) a moisture treatment in which an attached $17 \mathrm{~mm}$ long tube was filled with water and its distal end sealed with silicone sealant. The tube in (i) was half length so as to minimise any increase in humidity in the tube-earlier experiments showed that microcracking can also result from exposure to high humidity $[16,19]$. This tube was also mounted in such a position that, although open to the atmosphere, rainwater could not enter it. All tubes were removed after $12 \mathrm{~d}$ and the fruit sampled for histological analysis after a further period of $8 \mathrm{~d}$ in the orchard.

(2) The time course of the duration of exposure to the atmosphere (Phase II) following removal of surface moisture was studied. The fruit surface was exposed to moisture at 31 DAFB (2019 season) for 6 or $12 \mathrm{~d}$ when the moisture treatment was terminated and the time course of exposure to the atmosphere began. Fruit were sampled for microcracking, CM strain and histology at 0, 1, 2, 3 or $4 \mathrm{~d}$ after termination of moisture exposure (Phase II) or at maturity (156 DAFB).

(3) The time course of the duration of moisture exposure (Phase I) was studied by exposing fruit surfaces from 21 DAFB (2018 season) or 31 DAFB (2019 season) onwards to moisture for 0, 2, 4, 6, 8, 12 or $16 \mathrm{~d}$. Fruit were sampled either immediately after termination of the moisture treatment for microcracking, CM strain and histology or at maturity (156 DAFB) to quantify the frequency of fruit with russet and the percentage of russeted surface area.

(4) A developmental time course was established to identify any changes in periderm formation during fruit development. Moisture was applied to the surface of developing fruit, beginning at 31, 66 or 93 DAFB (2019 season) for $12 \mathrm{~d}$ (Phase I) and fruit were sampled $8 \mathrm{~d}$ after termination of the moisture treatment (Phase II). At this time, any periderm formed was clearly detectable by microscopy. Some fruit were left on the tree, sampled at maturity (156 DAFB) and used to quantify the frequency of fruit with russet and the percentage of russeted surface area.

\subsection{Data Analyses and Presentation}

Data are presented as means \pm SE. Where error bars are not visible, they were smaller than data symbols. Data for strain relaxation analysis and cuticle thickness were subjected to one-way analysis of variance (ANOVA) using SAS (Version 9.1.3; SAS Institute, Cary, NC, USA). Means were compared using Tukey's studentized test at $p \leq 0.05$.

Supplementary Materials: The following is available online at http://www.mdpi.com/2223-7747/9/10/1293/s1, Supplementary Table S1: Meteorological data.

Author Contributions: Conceptualization, M.K., T.D. and B.P.K.; funding acquisition, M.K. and T.D.; project administration, M.K. and T.D.; methodology, M.K., T.D. and B.P.K.; investigation, Y.-H.C., J.S. and B.P.K.; supervision, M.K., T.D. and B.P.K.; data curation, Y.-H.C., J.S. and B.P.K.; validation, Y.-H.C., J.S. and B.P.K.; visualization, Y.-H.C., J.S. and B.P.K.; formal analysis, Y.-H.C., J.S. and B.P.K.; Writing-Original draft, M.K., Y.-H.C. and B.P.K.; and Writing-Review and editing, M.K., Y.-H.C. and B.P.K. All authors have read and agreed to the published version of the manuscript.

Funding: This research was funded by a grant (KN 402) from the Deutsche Forschungsgemeinschaft (DFG). The publication of this article was funded by the Open Access fund of the Leibniz Universität Hannover.

Acknowledgments: We thank Traud Winkelmann and Raul Javier Morales Orellana for advice and support in sample preparation for histology. We also thank Simon Sitzenstock and Friederike Schröder for technical assistance, Alexander Lang for helpful comments on the earlier version of this manuscript and the Institue of Meterology and Climatology, Leibniz University Hannover for making the weather records available to us.

Conflicts of Interest: There are no known competing interests that could influence the work reported in this paper.

\section{References}

1. Skene, D.S. The development of russet, rough russet and cracks on the fruit of the apple Cox's Orange Pippin during the course of the season. J. Hortic. Sci. 1982, 57, 165-174. [CrossRef]

2. Scharwies, J.D.; Grimm, E.; Knoche, M. Russeting and relative growth rate are positively related in 'Conference' and 'Condo' pear. HortScience 2014, 49, 746-749. [CrossRef] 
3. Goffinet, M.C.; Pearson, R.C. Anatomy of russeting induced in Concord grape berries by the fungicide chlorothalonil. Am. J. Enol. Vitic. 1991, 42, 281-289.

4. Michailides, T.J. Russeting and russet scab of prune, an environmentally induced fruit disorder: Symptomatology, induction, and control. Plant Dis. 1991, 75, 1114-1123. [CrossRef]

5. Khanal, B.P.; Ikigu, G.M.; Knoche, M. Russeting partially restores apple skin permeability to water vapour. Planta 2019, 249, 849-860. [CrossRef]

6. Evert, R.F. Esau's Plant Anatomy: Meristems, Cells, and Tissues of the Plant Body: Their Structure, Function, and Development, 3rd ed.; John Wiley \& Sons: Hoboken, NJ, USA, 2006.

7. Macnee, N.C.; Rebstock, R.; Hallett, I.C.; Schaffer, R.J.; Bulley, S.M. A review of current knowledge about the formation of native peridermal exocarp in fruit. Funct. Plant Biol. 2020. [CrossRef] [PubMed]

8. Schreiber, L.; Franke, R.; Hartmann, K. Wax and suberin development of native and wound periderm of potato (Solanum tuberosum L.) and its relation to peridermal transpiration. Planta 2005, 220, 520-530. [CrossRef]

9. Simons, R.K.; Aubertin, M. Development of epidermal, hypodermal and cortical tissues in the Golden Delicious apple as influenced by induced mechanical injury. Proc. Am. Soc. Hortic. Sci. 1959, 74, 10-24.

10. Creasy, L.L.; Swartz, H.J. Agents influencing russet in 'Golden Delicious' apple fruit. J. Am. Soc. Hortic. Sci. 1981, 106, 203-206.

11. Sanchez, E.; Soto, J.M.; Uvalle, J.X.; Hernandez, A.P.; Ruiz, J.M.; Romero, L. Chemical treatments in "Golden Delicious spur" fruits in relation to russeting and nutritional status. J. Plant Nutr. 2001, 24, 191-202. [CrossRef]

12. Jones, K.M.; Bound, S.A.; Oakford, M.J.; Wilson, D. A strategy for reducing russet in Red Fuji apples while maintaining control of black spot (Venturia inaequalis). Aust. J. Exp. Agric. 1994, 34, 127-130. [CrossRef]

13. Gildemacher, P.; Heijne, B.; Silvestri, M.; Houbraken, J.; Hoekstra, E.; Theelen, B.; Boekhout, T. Interactions between yeasts, fungicides and apple fruit russeting. FEMS Yeast Res. 2006, 6, 1149-1156. [CrossRef]

14. Easterbrook, M.A.; Fuller, M.M. Russeting of apples caused by apple rust mite Aculus schlechtendali (Acarina: Eriophyidae). Ann. Appl. Biol. 1986, 109, 1-9. [CrossRef]

15. Lindow, S.E.; Desurmont, C.; Elkins, R.; McGourty, G.; Clark, E.; Brandl, M.T. Occurrence of indole-3-acetic acid-producing bacteria on pear trees and their association with fruit russet. Phytopathology 1998, 88, 1149-1157. [CrossRef] [PubMed]

16. Knoche, M.; Grimm, E. Surface moisture induces microcracks in the cuticle of 'Golden Delicious' apple. HortScience 2008, 43, 1929-1931. [CrossRef]

17. Knoche, M.; Khanal, B.P.; Stopar, M. Russeting and microcracking of 'Golden Delicious' apple fruit concomitantly decline due to gibberellin A4+7 application. J. Am. Soc. Hortic. Sci. 2011, 136, 159-164. [CrossRef]

18. Winkler, A.; Grimm, E.; Knoche, M.; Lindstaedt, J.; Köpcke, D. Late-season surface water induces skin spot in apple. HortScience 2014, 49, 1324-1327. [CrossRef]

19. Tukey, L.D. Observations on the russeting of apples growing in plastic bags. Proc. Am. Soc. Hortic. Sci. 1959, 74, 30-39.

20. Faust, M.; Shear, C.B. Russeting of apples, an interpretive review. HortScience 1972, 7, 233-235.

21. Faust, M.; Shear, C.B. Fine structure of the fruit surface of three apple cultivars. J. Am. Soc. Hortic. Sci. 1972, 97, 351-355.

22. Meyer, A. A Study of the skin structure of 'Golden Delicious' apples. J. Am. Soc. Hortic. Sci. 1944, 45, 105-110.

23. Khanal, B.P.; Knoche, M. Mechanical properties of cuticles and their primary determinants. J. Exp. Bot. 2017, 68, 5351-5367. [CrossRef] [PubMed]

24. Khanal, B.P.; Imoro, Y.; Chen, Y.H.; Straube, J.; Knoche, M. Surface moisture increases microcracking and water vapor permeance of apple fruit skin. Plant Biol. 2020. [CrossRef] [PubMed]

25. Pratt, C. Periderm development and radiation stability of russet-fruited sports of apple. Hortic. Res. 1972, 12, 5-12.

26. Simons, R.K.; Chu, M.C. Periderm morphology of mature 'Golden Delicious' apple with special reference to russeting. Sci. Hortic. 1978, 8, 333-340. [CrossRef]

27. Wertheim, S.J. Fruit russeting in apple as affected by various gibberellins. J. Hortic. Sci. 1982, 57, $283-288$. [CrossRef] 
28. Creasy, L.L. The correlation of weather parameters with russet of Golden Delicious apples under orchard conditions. J. Am. Soc. Hortic. Sci. 1980, 105, 735-738.

29. Lai, X.; Khanal, B.P.; Knoche, M. Mismatch between cuticle deposition and area expansion in fruit skins allows potentially catastrophic buildup of elastic strain. Planta 2016, 244, 1145-1156. [CrossRef]

30. Khanal, B.P.; Knoche, M. Mechanical properties of apple skin are determined by epidermis and hypodermis. J. Am. Soc. Hortic. Sci. 2014, 139, 139-147. [CrossRef]

31. Knoche, M.; Peschel, S. Water on the surface aggravates microscopic cracking of the sweet cherry fruit cuticle. J. Am. Soc. Hortic. Sci. 2006, 131, 192-200. [CrossRef]

32. Becker, T.; Knoche, M. Deposition, strain, and microcracking of the cuticle in developing 'Riesling' grape berries. Vitis 2012, 51, 1-6. [CrossRef]

33. Athoo, T.O.; Winkler, A.; Knoche, M. Russeting in 'Apple' mango: Triggers and mechanisms. Plants 2020, 9, 898. [CrossRef] [PubMed]

34. Knoche, M.; Beyer, M.; Peschel, S.; Oparlakov, B.; Bukovac, M.J. Changes in strain and deposition of cuticle in developing sweet cherry fruit. Physiol. Plant. 2004, 120, 667-677. [CrossRef] [PubMed]

35. Peschel, S.; Knoche, M. Characterization of microcracks in the cuticle of developing sweet cherry fruit. J. Am. Soc. Hortic. Sci. 2005, 130, 487-495. [CrossRef]

36. Khanal, B.P.; Grimm, E.; Finger, S.; Blume, A.; Knoche, M. Intracuticular wax fixes and restricts strain in leaf and fruit cuticles. New Phytol. 2013, 200, 134-143. [CrossRef]

37. Khanal, B.P.; Knoche, M.; Bußler, S.; Schlüter, O. Evidence for a radial strain gradient in apple fruit cuticles. Planta 2014, 240, 891-897. [CrossRef]

38. Karnovsky, M.J. A formaldehyde-glutaraldehyde fixative of high osmolarity for use in electron microscopy. J. Cell Biol. 1965, 27, 1A-149A.

39. Brundrett, M.C.; Kendrick, B.; Peterson, C.A. Efficient lipid staining in plant material with Sudan Red 7B or Fluoral Yellow 088 in polyethylene glycol-glycerol. Biotech. Histochem. 1991, 66, 111-116. [CrossRef]

40. Orgell, W.H. The isolation of plant cuticle with pectic enzymes. Plant Physiol. 1955, 30, 78-80. [CrossRef]

(C) 2020 by the authors. Licensee MDPI, Basel, Switzerland. This article is an open access article distributed under the terms and conditions of the Creative Commons Attribution (CC BY) license (http://creativecommons.org/licenses/by/4.0/). 